\title{
Correction to: Structural Characteristics of Natural Loess in Northwest China and Its Effect on Shear Behavior
}

\author{
Yong Wang $\mathbb{B} \cdot$ Hui Yang $\cdot$ Xu Jing
}

Published online: 27 October 2020

(C) Springer Nature Switzerland AG 2020

\section{Correction to: Geotech Geol Eng https://doi.org/10.1007/s10706-020- \\ 01420-4}

Unfortunately, Figures 4 and 7 in the original article contained some oversights. The correct Figures and Figure Legends are provided below (Figs. 4, 7).

The original article can be found online at https:// doi.org/10.1007/s10706-020-01420-4.

\footnotetext{
Y. Wang $(\bowtie)$

Institute of Rock and Soil Mechanics, Chinese Academy of Sciences, Wuhan 430071, People's Republic of China e-mail: wangyong0811@outlook.com
}

Y. Wang $\cdot$ H. Yang $\cdot$ X. Jing Department of Geology, Northwest University, Xi' an 710069, People's Republic of China

H. Yang $\cdot$ X. Jing

State Key Laboratory of Continental Dynamics,

Northwest University, Xi'an 710069, People's Republic

of China 


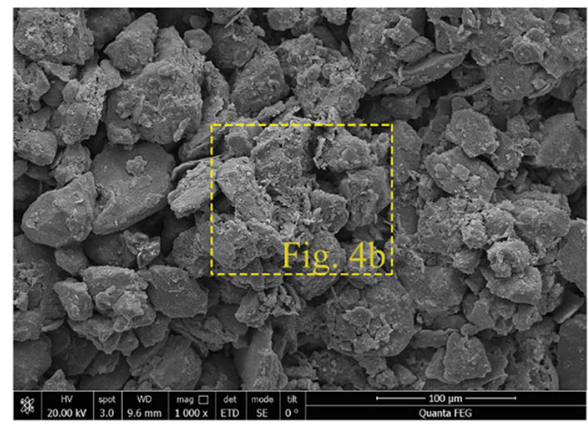

(a)

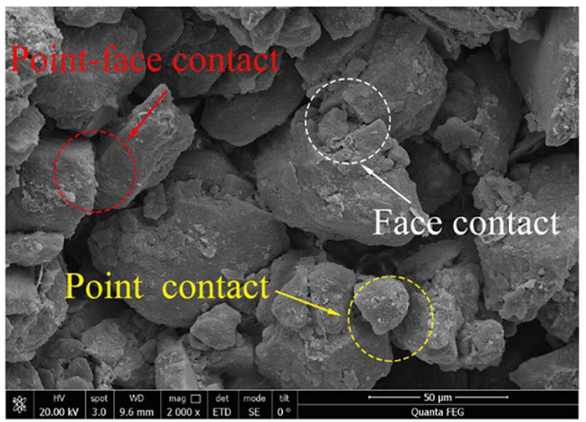

(b)

Fig. 4 SEM images of samples at initial state: a an overview; $\mathbf{b}$ local view

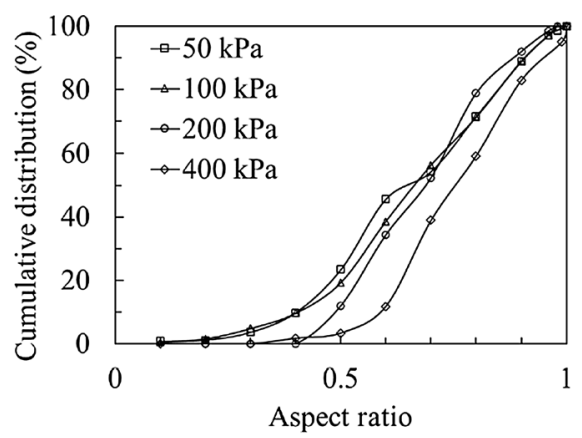

(a)

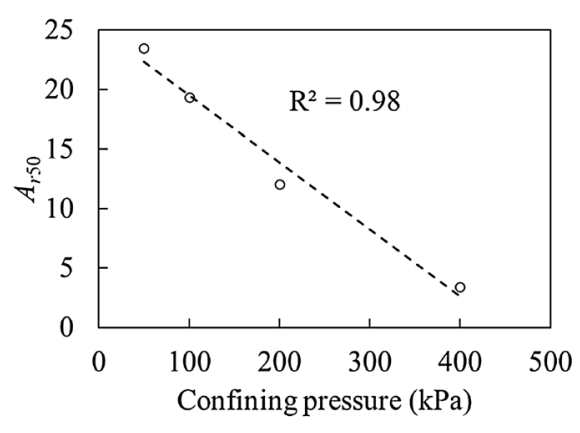

(b)

Fig. 7 Aspect ratio: a cumulative distribution curve; $\mathbf{b}$ correlation of $A_{\mathrm{r} 50}$ with confining pressure

Publisher's Note Springer Nature remains neutral with regard to jurisdictional claims in published maps and institutional affiliations. 